Wei Li

Xue Zhong Yu

\section{Is it true that activation \\ of the renin-angiotensin system could induce natriuresis?}

Accepted: 9 January 2015

Published online: 30 January 2015

(C) Springer-Verlag Berlin Heidelberg and ESICM 2015

Dear Editor,

In their newly published paper

"What's new with hypertensive crises?", Monnet and Marik [1] stated

"Hypertensive emergencies are frequently associated with hypovolemia due to natriuresis induced by activation of the renin-angiotensin system". This viewpoint is not absolutely correct.

In states of hypertensive emergencies, both angiotensin II and aldosterone levels are high as a result of activation of the renin-angiotensin system. Angiotensin II activates the sodium chloride cotransporter located in the distal convoluted tubule through phosphorylation by Ste20related proline-alanine-rich kinase, an effect that is independent of aldosterone. Moreover, aldosterone alone can also increase the sodium chloride cotransporter [2]. In addition, angiotensin II activated another sodium transporter in the distal nephron, namely the epithelial sodium channel as well as aldosterone. Angiotensin II acutely increased the open probability of the epithelial sodium channel, and longer exposure to angiotensin II (30 $\mathrm{min}$ ) also induced a translocation of the epithelial sodium channel to the apical plasma membrane. Of interest, aldosterone did not increase the expression of the epithelial sodium channel. Thus, angiotensin II has an additive effect to aldosterone in the activation of the epithelial sodium channel, similar to what we showed for the sodium chloride cotransporter [3, 4]. All in all, the net effect of the renin-angiotensin system is to make the kidneys retain sodium and water. So, activation of the reninangiotensin system has no association with hypovolemia, but reabsorbs more sodium and water. Furthermore, circulating angiotensin II, as a kind of vaso-excitor material, directly constricts afferent and efferent glomerular arterioles, which results in glomerular filtration rate reduction. So, physicians must keep alert in cases of acute kidney injury in patients with hypertensive emergencies. Cystatin $\mathrm{C}$ is a helpful biomarker presumed to allow the early detection of small declines in the glomerular filtration rate [5]. Angiotensin II also combines with related receptors located in the brain to stimulate the release of vasopressin and adrenocorticotropic hormone to accelerate sympathetic activity. All mechanisms could lead to the aggravation of hypertensive emergencies.

Actually, under hypertensive emergencies, both the resistance of systemic circulation and cardiac afterload increase, blood flow has to surmount greater resistance to fill the heart, which leads to more blood volume stranded in the venous system, and, what is worse, long-term microvascular constriction increases permeability of small vessels and causes fluid leakage. These mechanisms may contribute to hypovolemia, especially in the arterial system.

The authors also referred to the usage of diuretics in hypertensive crises. Diuretics are not recommended to treat hypertensive crises, because further loss of fluids may exacerbate the activation of the renin-angiotensin system as a result of degenerative feedback.

\section{References}

1. Monnet X, Marik PE (2015) What's new with hypertensive crises. Intensive Care Med 41:127-130. doi 10.1007/s00134-014-3546-7

2. Van der Lubbe N, Lim CH, Meima ME, van Veghel R, Rosenbaek LL, Mutig K, Danser AH, Fenton RA, Zietse R, Hoorn EJ (2012) Aldosterone does not require angiotensin II to activate NCC through a WNK4-SPAK-dependent pathway. Pflugers Arch 463:853-863

3. Mamenko M, Zaika O, Ilatovskaya DV, Staruschenko A, Pochynyuk O (2012) Angiotensin II increases activity of the epithelial $\mathrm{Na}^{+}$channel(ENaC) in distal nephron additively to aldosterone. J Biol Chem 287:660-671

4. Sun P, Yue P, Wang WH (2012)

Angiotensin II stimulates epithelial sodium channels in the cortical collecting duct of the rat kidney. Am J Physiol Renal Physio 302:F679-F687

5. Citerio G, Bakker J, Bassetti M et al (2014) Year in review in Intensive Care Medicine 2013: I. Acute kidney injury, ultrasound, hemodynamics, cardiac arrest, transfusion, neurocritical care, and nutrition. Intensive Care Med 40(2):147-159

W. Li · X. Z. Yu (ه)

Peking Union Medical College Hospital (PUMCH), Chinese Academy of Medical Sciences, Beijing, China e-mail: yxzmed@126.com 